\title{
A paisagem urbana viária na perspectiva do pedestre: estudo da Avenida Nações Unidas em Bauru/SP
}

The urban road landscape in the pedestrian's perspective: study of Nações Unidas Avenue in Bauru/SP

El paisaje urbano de las vías en la perspectiva de los peatones: estudio de la Avenida Nações Unidas en Bauru/SP

\section{Maria Clara Ortega Pichinin}

Mestranda, UNESP, Brasil. mariaclara_ortega@hotmail.com

\section{Fernanda Moço Foloni}

Mestranda, UNESP, Brasil. fe_foloni@hotmail.com

Norma Regina Truppel Constantino ProfessoraDoutora, UNESP, Brasil. nconst@faac.unesp.br 




ocorrência provável visto que as tecnologias avançadas que temos na atualidade fabricam a ideia de que qualquer empecilho que poderíamos encontrar na natureza pode ser facilmente ignorado (CORAJOUD, 2011, p.223).

As cidades são vistas na Idade Média e até pelos gregos como um espaço libertador, neste ambiente os cidadãos não teriam as preocupações com a natureza (TUAN, 1980, p.172). Ao pensar uma cidade em qualquer período histórico ou localização, é impossível imaginá-la sem ruas, pois seu traçado está diretamente ligado a sua formação. É uma das bases para o espaço urbano, inicialmente pensado para os pedestres e animais (LAMAS, 2011, p.152).

Werf, Zweerink e Teeffelen (2015, p.36) consideram a cidade um centro de trocas, e dizem que a vibração que existia nas ruas foi modificada a partir dos anos de 1960 e 1970, com a preocupação que passou a existir com o trânsito. Para Tuan (1980, p.219), o automóvel é responsável por mudanças na relação do homem com o meio urbano. Uma das características dessa mudança foi o sentimento de orgulho que as grandes obras viárias traziam, acompanhadas por uma visão de mundo na qual quanto mais a paisagem era transformada, mais desenvolvida era a sociedade.

Os conceitos aqui reunidos nos conduzem então a observar a paisagem para interpretar o ambiente construído nas cidades, determinantes na vida de seus usuários. Ao estudar a paisagem, é possível estabelecer a história de um lugar e definir características para o espaço urbano, que devem se relacionar com seu local de inserção.

Observando o processo histórico da Avenida Nações Unidas, existem vários registros das transformações da paisagem decorrentes desta obra, algumas intencionais para o projeto, outras consequências previstas ou não. A Figura 1 apresenta dois mapas do centro de Bauru, obtidos no arquivo histórico do Núcleo de Pesquisa e História da Universidade do Sagrado Coração (NUPHIS-USC).

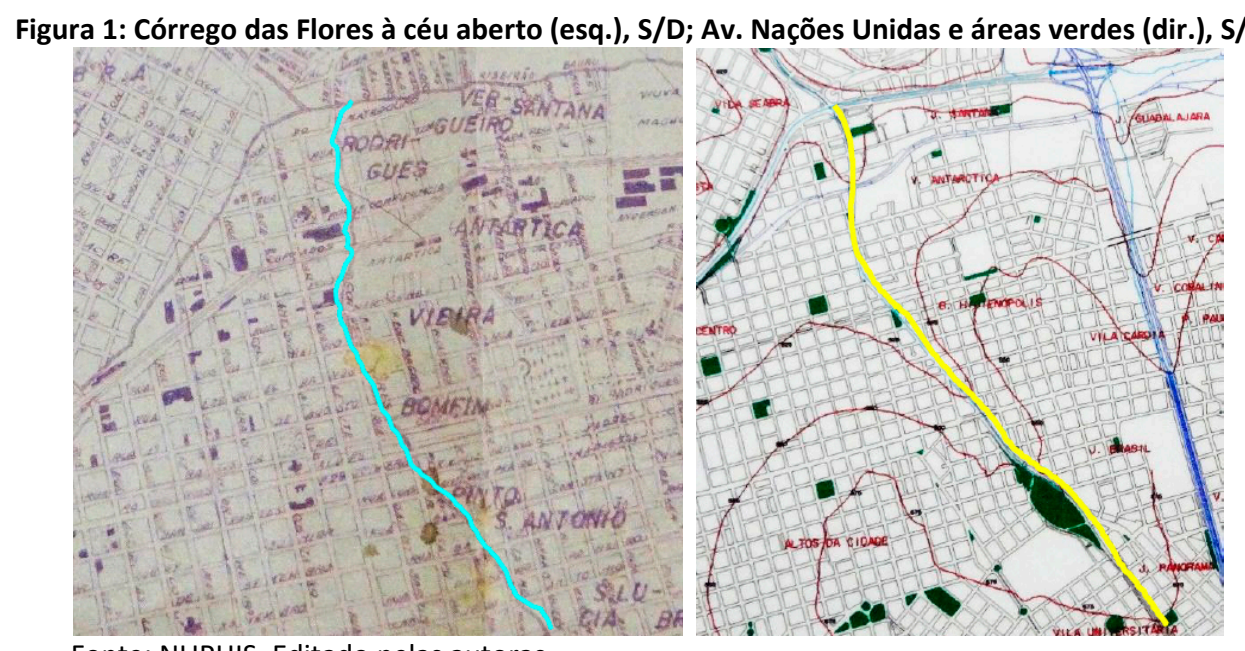

Fonte: NUPHIS. Editado pelas autoras.

No primeiro mapa, do início do século XX e anterior à década de 70, é possível perceber a malha urbana quadriculada ininterrupta, mesmo com a presença do Córrego das Flores à céu aberto 




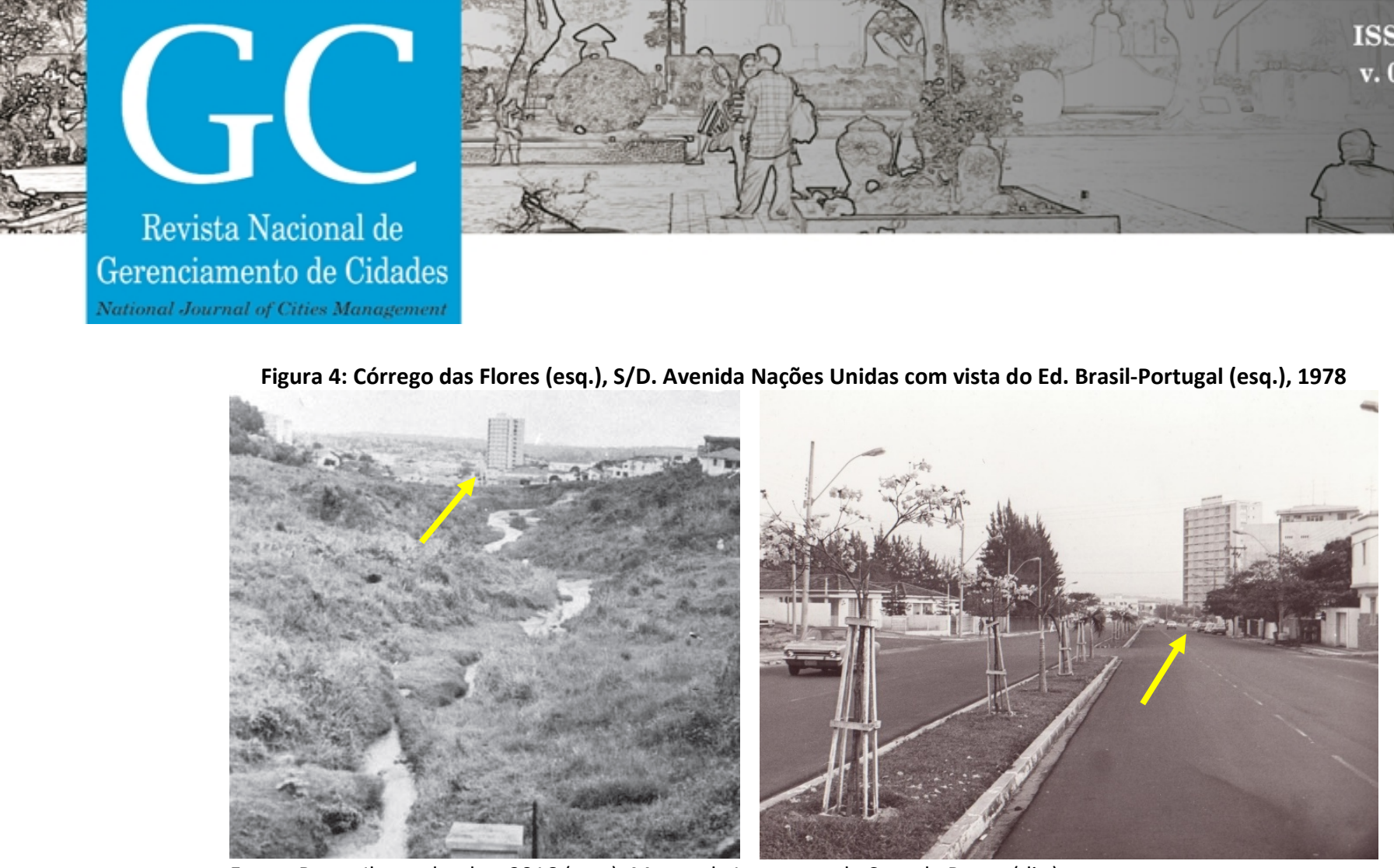

Fonte: Bauru Ilustrado, dez. 2016 (esq.). Museu da Imagem e do Som de Bauru (dir.).

Figura 5: Feira livre na Praça do Líbano (esq.), 1971. Projeto para mesma finalizado (dir.), 1971
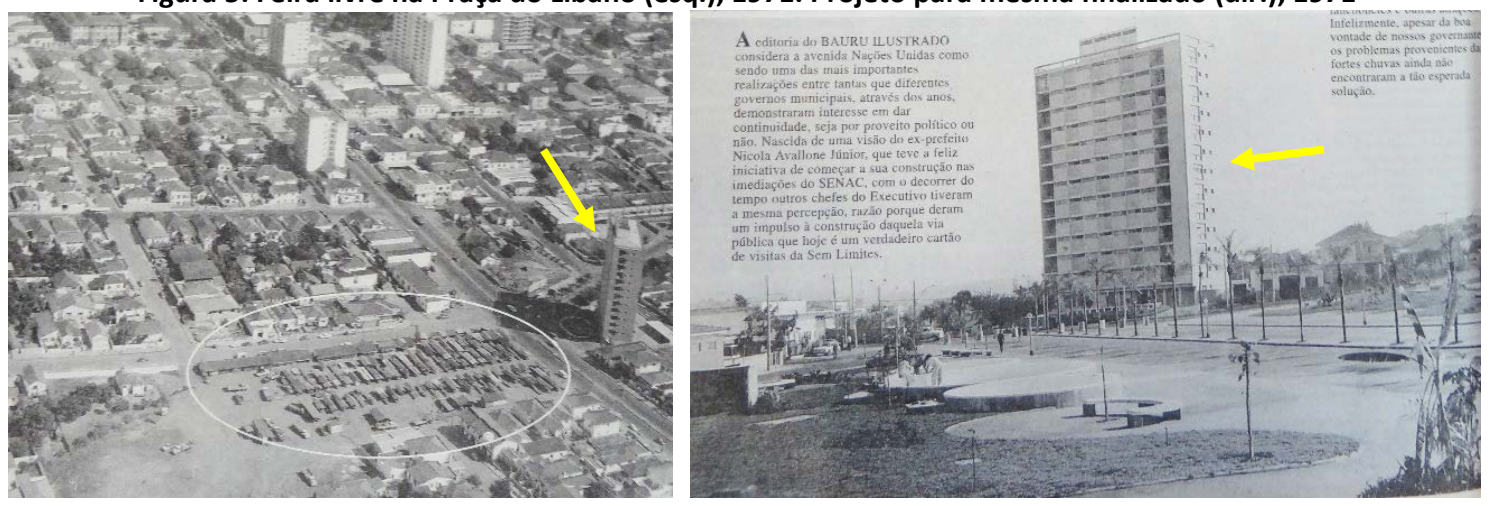

Fonte: Bauru llustrado,set. 1997.

A Figura 5 ainda mostra outro resultado importante na transformação do uso do espaço: na imagem à esquerda encontra-se circulado um lugar apropriado pelas pessoas para realização de uma feira livre permanente, no cruzamento da Av. Nações Unidas com a Av. Rodrigues Alves. Pouco tempo depois, dentre as várias reformas urbanas, este local foi remodelado e inaugurado como Praça República do Líbano (Figura 5 à direita), homenageando a comunidade libanesa bauruense na gestão do prefeito Alcides Franciscato, inaugurada em 1971, com projeto do arquiteto Jurandyr Bueno Filho.

A localização dessa praça na região central de Bauru, somada à arborização introduzida e bancos para descanso, atraiu restaurantes e lanchonetes ${ }^{6}$. Até hoje seu uso é constante, mas os alagamentos no local são um problema frequente, pois danificam o espaço. Outra atração para a população localizada na Av. Nações Unidas - além do Parque das Nações (hoje conhecido como Parque Vitória Régia) inaugurado em 1978 (LOSNAK, 2004, p.173) junto às obras da via,

\footnotetext{
${ }^{6}$ Segundo a matéria do Bauru llustrado, p.10, set. 1997. Disponível para consulta no Museu Histórico Municipal de Bauru.
} 



CLOS, J. Prólogo. In: KARSSENBERG, H. et al. (Ed.). A cidade ao nível dos olhos: lições para os plinths. 2. ed. Porto Alegre: Pontifícia Universidade Católica do RS, 2015. v. 2. Disponível em: <http://www.pucrs.br/edipucrs>. Acesso em: 28 set. 2016. p.86-89.

CORAJOUD, M. A paisagem é o lugar onde o céu e a terra se tocam. In: SERRÃO, A. V. S. (Coord.). Filosofia da paisagem: Uma Antologia. Lisboa: Centro de Filosofia da Universidade de Lisboa, 2011. p.215-225.

GEHL, J. Cidades para pessoas. 3. ed. São Paulo: Editora Perspectiva, 2015

LAMAS, J. M. R. G. Morfologia urbana e desenho da cidade. 6. ed. Lisboa: Calouste Gulbenkian, 2011.

JORGE, J. D. G. O tempo da cidade. In: SERRÃO, A. V. S. (coord.). Filosofia e arquitectura da paisagem: intervenções. Lisboa: Centro de Filosofia da Universidade de Lisboa, 2013. p.179-185.

KARSSENBERG, H. et al. (ed.). A cidade ao nível dos olhos: lições para os plinths. 2. ed. Porto Alegre: Pontifícia Universidade Católica do RS, 2015. v. 2. Disponível em: <http://www.pucrs.br/edipucrs>. Acesso em: 28 set. 2016.

KENT, F.; MADDEN, K. Rua como lugares. In: KARSSENBERG, H. et al. (Ed.). A cidade ao nível dos olhos: lições para os plinths. 2. ed. Porto Alegre: Pontifícia Universidade Católica do RS, 2015. v. 2. Disponível em: <http://www.pucrs.br/edipucrs >. Acesso em: 28 set. 2016. p.26-28.

KNUIJT, M. Os altos e baixos do espaço público. In: KARSSENBERG, H. et al. (Ed.). A cidade ao nível dos olhos: lições para os plinths. 2. ed. Porto Alegre: Pontifícia Universidade Católica do RS, 2015. v. 2. Disponível em: <http://www.pucrs.br/edipucrs>. Acesso em: 28 set. 2016. p.86-89.

LOSNAK, C. J. Polifonia urbana: imagens e representações - Bauru 1950-1980. Bauru, SP: EUDUSC, 2004.

REKER, M.; PASTORE, J.B. Uma intervenção paisagística no espaço urbano. In: SERRÃO, A. V. S. (Coord.). Filosofia e arquitectura da paisagem: intervenções. Lisboa: Centro de Filosofia da Universidade de Lisboa, 2013. p.199-211.

SERRÃO, A. V. Paisagem, Permanência e Instabilidade em movimenti di um tempo impossible. In: SERRÃO, A. V. S. (Coord.). Filosofia e arquitectura da paisagem: intervenções. Lisboa: Centro de Filosofia da Universidade de Lisboa, 2013. p.105-109.

TUCCI, C. E. M. Águas urbanas. In: Estudos avançados, São Paulo, v.22, n.63, 2008.

TUAN, Y. Topofilia: um estudo da percepção, atitudes e valores do meio ambiente. São Paulo: DIFEL, 1980.

VERAS, L. et al. Cadernos de arquitetura e urbanismo: cidade-paisagem. Recife: Conselho de Arquitetura e Urbanismo de Pernambuco (CAU/PE); João Pessoa: Patmos Editora, 2017. v. 2.

SPECK, J. Cidade caminhável. Editora Perspectiva SA, 2016.

WERF, J. V. D.; ZWEERINK K.; TEEFFELEN, J. V. História da cidade, rua e andar térreo. In: KARSSENBERG, H. et al. (Ed.). A cidade ao nível dos olhos: lições para os plinths. 2. ed. Porto Alegre: Pontifícia Universidade Católica do RS, 2015. v. 2. Disponível em: <http://www.pucrs.br/edipucrs>. Acesso em: 28 set. 2016. p.36-47. 